DOT/FAA/AM-97/4

Office of Aviation Medicine

Washington, D.C. 20591
The Effects of Video Game .

Experience on Computer-Based

Air Traffic Controller Specialist, Air Traffic Scenario Test Scores
Willie C. Young

Dana Broach

William L. Farmer

Civil Aeromedical Institute

Federal Aviation Administration

Oklahoma City, Oklahoma 73125

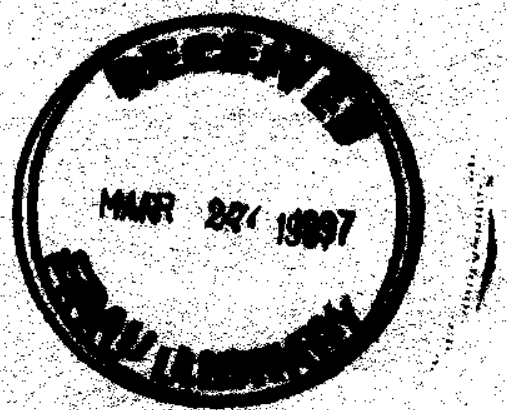

February 1997

Final Report

This document is available to the public

through the National Technical Information

Service, Springfield, Virginia 22161.
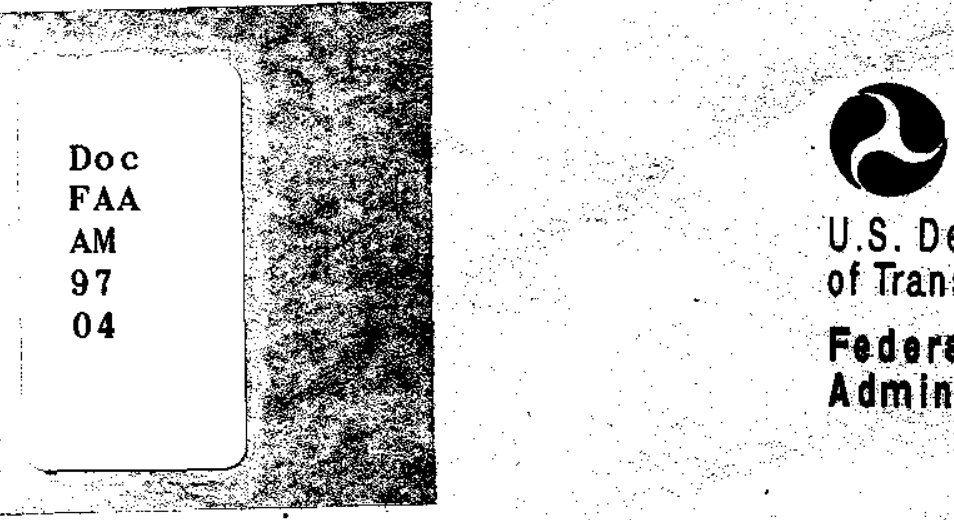

U.S. Department

of Transportation

Fedoral Avallon Administration 
Technical Documentation Page

\begin{tabular}{|c|c|c|}
\hline $\begin{array}{l}\text { 1. Report No. } \\
\text { DOT/FAA/AM-97/4 }\end{array}$ & 2. Government Accession No. & 3. Recipient's Catalog No. \\
\hline \multirow{2}{*}{\multicolumn{2}{|c|}{$\begin{array}{l}\text { 4. Title and Subtitle } \\
\text { The Effects of Video Game Experience on Computer-Based Air Traffic } \\
\text { Controller Specialist, Air Traffic Scenario Test Scores }\end{array}$}} & $\begin{array}{l}\text { 5. Report Date } \\
\text { February } 1997\end{array}$ \\
\hline & & 6. Performing Organization Code \\
\hline \multicolumn{2}{|c|}{$\begin{array}{l}\text { 7. Author(s) } \\
\text { Young, W.C., M.Ed.; Broach, D., Ph.D.; \& Farmer, W.L., M.S. }\end{array}$} & 8. Performing Organization Report No. \\
\hline \multirow{3}{*}{\multicolumn{2}{|c|}{$\begin{array}{l}\text { 9. Performing Organization Name and Address } \\
\text { FAA Civil Aeromedical Institute } \\
\text { P.O. Box } 25082 \\
\text { Oklahoma City, OK } 73125\end{array}$}} & 10. Work Unit No. (TRAIS) \\
\hline & & \\
\hline & & 11. Contract or Grant No. \\
\hline \multicolumn{2}{|c|}{$\begin{array}{l}\text { 12. Sponsoring Agency Name and Address } \\
\text { Office of Aviation Medicine } \\
\text { Federal Aviation Administration } \\
800 \text { Independence Avenue, S. W. } \\
\text { Washington, DC } 20591\end{array}$} & 13. Type of Report and Period Covered \\
\hline
\end{tabular}

16. Abstract

The FAA is currently using the Air Traffic Scenario Test (ATST) as a major portion of its selection process. Because the ATST is a PC - based application with a strong resemblance to a video game, concern has been raised that prior video game experience might have a moderating effect on scores. Much of the previous research in this area is associated with topics such as the moderating effects of prior computer experience on scores earned on computerized versions of traditional achievement or power tests (Lee, 1986), and the effects of practice on video games on individual difference tests for constructs such as spatial ability (Dorval \& Pepin, 1986; Lohman, 1979). The effects of computer or video game experience on work sample scores have not been systematically investigated. The purpose of this study was to evaluate the incremental validity of prior video game experience over that of general aptitude as a predictor of work sample test scores.

The Computer Use Survey was administered to 404 air traffic control students who entered the FAA ATCS Nonradar Screen. The resultant responses from this survey related to video games were summed and averaged to create the predictor (VIDEO). Three criterion measures derived from the ATST, (ATSAFE, ARVDELAY, HNDDELAY) were regressed on the cognitive aptitude measure that serves as the initial selection screening test and the predictor (VIDEO). Self-reported experience on video games was found to be significantly related to ARVDELAY and HNDDELAY, accounting for an additional $3.6 \%$ of the variance in ARVDELAY, and accounting for an additional 9\% of the variance in HNDDELAY. The results suggested that those persons with video game experience were more efficient at hand-offs and routing aircraft. Future research is recommended to investigate the effect of prior video game experience on learning curves and strategies used in the work sample test.

17. Key Words

Video games; Selection; Computer; Screen; Hierarchical regression; Air Traffic Scenario Test
18. Distribution Statement

Document is available to the public through the National Technical Information Service, Springfield, VA 22161

\begin{tabular}{|c|c|c|c|}
\hline $\begin{array}{c}\text { 19. Security Classif. (of this report) } \\
\text { Unclassified }\end{array}$ & $\begin{array}{c}\text { 20. Security Classif. (of this page) } \\
\text { Unclassified }\end{array}$ & $\begin{array}{c}21 . \text { No. of Pages } \\
13\end{array}$ & 22. Price \\
\hline
\end{tabular}

Form DOT F 1700.7 (8-72)

Reproduction of completed page authorized 


\section{The Effects of Video Game Experience on Computer-Based Air Traffic Controller Specialist, Air Traffic Scenario Test Scores}

\section{INTRODUCTION}

The FAA undertook a major review of its Air Traffic Control Specialist (ATCS) selection and training programs in 1990 to address agency and applicant costs and other concerns. Three major ATCS selection policy goals were identified for the project: (1) reduce the cost of the ATCS selection process, (2) maintain the validity of the ATCS selection system, and (3) support agency cultural diversity goals. The first step toward achieving these goals was to develop and validate a test battery to replace the 9-week FAA Academy Nonradar ATCS Screen that serves as the second major hurdle in the agency's multiple hurdle selection process (Broach \& Brecht - Clark, 1993).

Development of the new Pre-Training Screen (PTS) test battery began in late 1990 by reviewing available information about the cognitive requirements of the ATCS job. As described in one cognitive task analysis, controllers attend to multiple information sources, assess and integrate the data, develop and prioritize plans of action, and implement those plans under time pressure while maintaining situational awareness (Human Technology, Inc., 1991). To assess the cognitive and sensory attributes required to perform these job functions, the PTS test battery was developed by Aerospace Sciences, Inc. (ASI). Two computer-administered information processing tests were designed to dynamically assess cognitive attributes, such as spatial reasoning, short-term memory, movement detection, pattern recognition, and attention allocation (ASI, 1991). In addition, the Air Traffic Scenario Test (ATST), a low-fidelity radar simulation of air traffic control vectoring and separation tasks, was developed as a computer administered work sample.

The ATST (Figure 1), is a computerized work sample test that was developed by 4 subject matter experts with more than 30 years of air traffic control experience (ASI, 1991). The task requires the subject to control aircraft within a simplified synthetic airspace, directing them to their destinations according to a small set of rules. The ATST runs on a 80386 class personal computer (PC) with a standard $640 \times 480$ 16-color VGA display. Because the ATST was a PC based application with a strong resemblance to a video game, concern was raised that prior video game experience might give some applicants an advantage over others in obtaining better scores. No data were available to evaluate this concern, as the relationship of prior computer or video game experience to performance on computerized work samples has not been investigated. Previous research on computerized tests has focused on topics such as the equivalence of computerized to paper-and-pencil formats (Finegan \& Allen, 1994; King \& Miles, in press; Lee, Moreno, \& Sympson, 1986; Lukin, Dowd, Plake, \& Kraft, 1985; Lushene, O’Neil, \& Dunn, 1974; Mazzeo \& Harvey, 1988; Mead \& Drasgow, 1993; Rabbit, Banerji, \& Szymanski, 1989; Vansickle, Kimmel, \& Kapes, 1989; Wilson, Genco, \& Yager, 1985), faking on computerized tests of non-cognitive constructs such as personality and biodata (Booth-Kewley, Edwards, \& Rosenfeld, 1992; Burke, 1992; Koson, Kitchen, Kochen, \& Stodolosky, 1970; Lautenschlager \& Flaherty, 1990; Martin \& Nagao, 1989; Potosky, 1996; Rosenfield, Giacalone, Knouse, Doherty, Mitchell-Vicino, Kantor, \& Greaves, 1991), the moderating effects of prior computer experience on scores earned on computerized versions of traditional achievement or power tests (Lee, 1986), and the effects of practice with video games on individual difference tests for constructs, such as spatial ability (Dorval \& Pepin, 1986; Lohman, 1979). The effects of computer or video game experience on work sample scores have not been systematically investigated. Aerospace Sciences, Inc. (ASI, 1991), in the course of validating the PTS, found that prior computer or video game experience did not moderate the validity of the composite PTS score as a predictor of performance in initial ATCS training at the FAA Academy. However, the relationship of prior computer experience to scores 
earned on the work sample test is unknown. The results of the previous study (ASI, 1991) suggested that the composite score earned on the PTS was an equally valid predictor of FAA Academy scores for persons with little or much prior computer or video game experience. However, the direct relationship of prior computer or video game experience to the final scores earned on the ATST was not investigated by ASI.

The purpose of this study, therefore, was to extend and refine the earlier ASI analysis, by evaluating the incremental validity of prior video game experience over that of general aptitude as a predictor of work sample test scores. A finding of no incremental validity for prior video game experience as a predictor of ATST scores would be supportive of the earlier ASI study involving composite PTS scores. However, a finding that video game experience did have incremental validity would indicate that a careful re-examination of the ASI-moderated validity analysis, in terms of the individual scores comprising the PTS composite, is warranted.

\section{METHOD}

\section{Sample}

The subjects for this study were 404 ait traffic control students who entered the FAA Academy ATCS Nonradar Screen in March and April of 1991. Sample demographic characteristics are presented in Table 1. The sample consisted primarily of non-minority males.

\section{Measures}

Aptitude score. The written ATCS aptitude tests comprising the initial hurdle in the ATCS selection process were: (a) the Multiplex Controller Aptitude Test (MCAT) and (b) the Abstract Reasoning Test (ABSR). The development, psychometric characteristics, and validity of these written ATCS aptitude tests have been extensively described elsewhere (Brokaw, 1984; Collins, Boone, \& VanDeventer, 1984; Manning, 1991; Sells, Dailey, \& Pickrel, 1984). Scoring of the tests was done by summing the MCAT (weighted .8) and ABSR (weighted .2) scores. The resulting weighted scores were then transformed to a score with

TABLE 1

Sample demographic characteristics

\begin{tabular}{lcc}
\hline & \multicolumn{2}{c}{$\begin{array}{c}\text { SEX } \\
(N=404)\end{array}$} \\
\cline { 2 - 3 } & Male & Female \\
\hline MEAN AGE & 26.5 & 26.3 \\
$\begin{array}{l}\text { EDUCATIONAL LEVEL } \\
\text { \% High School Only } \\
\text { \% Some College } \\
\text { \% College Degree }\end{array}$ & 13.9 & \\
$\begin{array}{l}\text { MiNORITY GROUP } \\
\text { \% Minority } \\
\text { \% Non-Minority }\end{array}$ & 44.3 & 10.4 \\
& 41.7 & 41.3 \\
& & 48.3 \\
\hline
\end{tabular}


a mean of 70 and maximum of 100 , known as the Transmuted Composite (TMC). About half of all applicants were expected to score at or above the mean (Rock, Dailey, Ozur, Boone, \& Pickrel, 1984a). Applicants with 3 years of general experience, 4 years of college, or any combination of education and experience equating to 3 years of general experience and without prior aviation experience, were required to earn a TMC of at least 75.1 to qualify for employment. Applicants not meeting these criteria were ineligible for employment as controllers. TMC was used in our analyses as the measure of candidate aptitude, as it provided a measure of ability unadjusted for previous experience and/or military service. Descriptive statistics for the TMC scores are presented in Table 2 for the research sample.

Predictor. The Computer Use Survey (CUS), was developed to assess prior usage and familiarity with personal computers and was used as the predictor in this study. The CUS (see Appendix) was modeled after a survey used by researchers at the NASA-Ames Research Center (S. Hart, personal communication, February 8, 1991), with 3 major blocks of items. First, respondents indicated the frequency of use of personal computers and software ( 8 items) on a 5-point Likert-type scale: $0=$ Never $;=$ Seldom; 2 = Sometimes; $3=$ Frequently; 4 = Often . Second, students indicated ownership of and training on the use of personal computers ( 9 items): $0=N o ; 1=$ Yes. Finally, the study participants indicated their proficiency on various kinds of video games ( 9 items) on the following 5 point Likert-type scale: $0=$ Never play; $1=$ Poor; 2 = Average; $3=$ Very good; and $4=$ Superior. Only the 9 items relating to video game experience were used in this analysis. Reliability $(\mathrm{a}=.82)$ and principal component analyses suggested that the 9 CUS items relating to video games were related in such a way as to support combining them in to 1 composite score. The values were summed and averaged to create the predictor variable, Video Game Average (VIDEO).

Criterion. The criterion in the analysis was performance on the Air Traffic Scenario Test. The ATST (Figure 1), required the subject to control aircraft within a simplified synthetic airspace, directing them to their destinations according to a small set of rules. There were 6 destinations: 4 outbound gates, A, B, C, and $D$; and 2 airports, $E$ and $F$. The direction of travel, speed, and altitude of the aircraft, represented by small arrows next to the quasi - data blocks, were controlled by mouse. Three alphanumeric characters comprised the quasi - data blocks: first, aircraft speed (Slow, Medium, Fast); second, altitude ( 1 = Lowest, through $4=$ Highest $)$; and third, destination. The orientation of the aircraft arrow indicated its current direction of flight. An open circle in an upper corner of the data block indicated an aircraft waiting to be activated by ("handed off to") the subject. The large arrow in the lower right-hand corner of the screen indicated the landing direction at airports $\mathrm{E}$ and $\mathrm{F}$, while the bottom horizontal bar icon represented the

TABLE 2

Sample descriptive statistics of predictors and criteria.

\section{Sample $(N=404)$}

\begin{tabular}{lrr} 
& $\boldsymbol{M}$ & $\boldsymbol{S}$ \\
& & \\
\hline TMC & 93.47 & 21.67 \\
VIDEO & 14.42 & 6.75 \\
ATSAFE & 20.81 & 21.67 \\
ARVDELAY & 32.53 & 36.37 \\
HNDDELAY & 57.81 & 17.34 \\
\hline
\end{tabular}




\section{FIGURE 1}

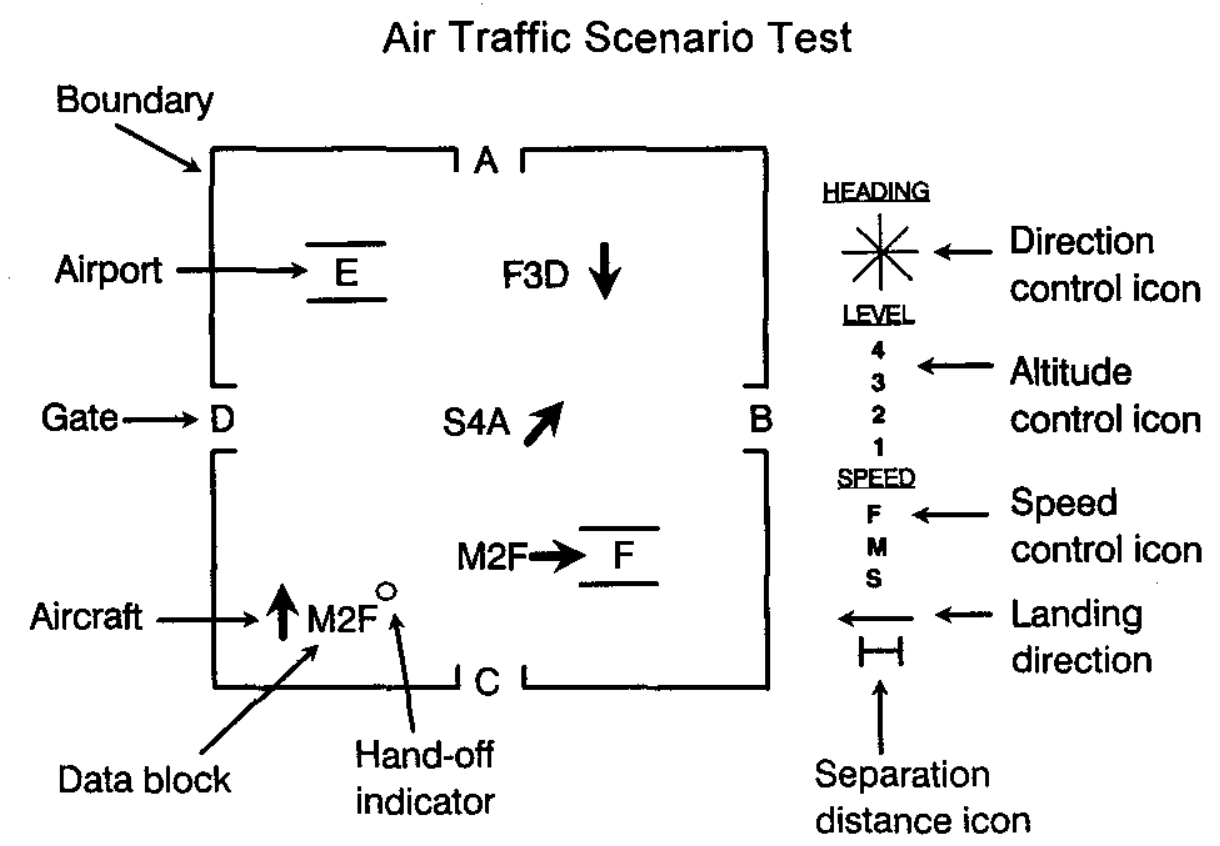

Figure 1. AIR TRAFFIC SCENARIO TEST (ATST) SCREEN. The boundary encloses a simplified airspace, with 4 outbound gates, $A, B, C$, and $D$, and 2 airports, $E$ and $F$. The aircraft and direction of flight are represented by the arrows adjacent to a data block. The alphanumeric data block indicates aircraft speed (Slow, Medium, or Fast) and altitude (1 $=$ lowest, $4=$ highest). Aircraft waiting to be handed off are tagged with a small open circle in the upper right hand corner of the data block. Aircraft are controlled with a mouse. First, the subject clicks on an aircraft, and then clicks on the appropriate element of either the direction control, altitude control, or speed control icons to change that flight parameter. Subjects are reminded of the required landing direction at airports and minimum horizontal separation distance by the landing direction and separation distance icons respectively.

minimum lateral separation distance. Aircraft landed at airports $\mathrm{E}$ and $\mathrm{F}$ at the lowest altitude and slow speed in the required direction; aircraft exited gates $A$, $B, C$, and $D$ at the fastest speed and highest altitude. A difference in altitude between any 2 aircraft was considered adequate separation; aircraft at the same altitude had to be separated by at least 5 nautical miles, as represented by the separation icon. In addition, all aircraft had to be separated from the airspace boundary by at least 5 nautical miles. Error counts associated with separation violations and crashes were obtained and summed with procedural errors such as exiting a gate at the wrong altitude to create an overall error score (ATSAFE). The system automatically computed the difference between the actual time to reach destination for each aircraft and the time required for the optimum flight path, as determined by the system software. Summed across aircraft, this arrival delay (ARVDELAY) provided a measure of subject efficiency in routing aircraft and managing the synthetic airspace. In addition, the system computed the difference between the time of appearance for an aircraft as a hand off and the time of acceptance. Averaged across new aircraft appearing in the scenarios, this hand off delay (HNDDELAY) provided a measure of subject efficiency in accepting new aircraft and managing workload. Performance feedback on these measures was provided to subjects at the end of each of 20 practice scenarios. The subjects for this study completed the 20 ATST practice sessions over 2.5 days (Monday afternoon through Wednesday), followed by the final 6 ATST "for grade" testing sessions on 
Thursday. The three criterion measures used for this study; Air Traffic Safety (ATSAFE), Arrival Delay (ARVDELAY), and Hand-off Delay (HNDDELAY), were computed using data from the final 6 ATST "for grade" testing sessions. A lower score represented better performance on each criterion measure. For example, higher scores for ATSAFE indicated that the subject had more crashes or committed more separation and procedural errors than a subject with a lower ATSAFE score. Similarly, higher scores on ARVDELAY and HNDDELAY indicated more delay time than a lower score.

\section{Procedure}

Multiple regression analysis was used to test the null hypothesis that the predictor variable Video Game Experience (VIDEO) had no incremental validity over Cognitive Aptitude scores (TMC) in the prediction of performance of the 3 criterion measures of ATST performance. The alternative hypothesis was that ATST error and delay scores decreased as video game experience increased, after taking in to account differences in general aptitude for the ATCS occupation. The amount of variance in ATSAFE accounted for by TMC was estimated in the first step of the analysis. Next, the performance measure was regressed on the predictor variable (VIDEO) in a hierarchical analysis to assess the incremental validity of the predictor. These steps were repeated using performance on ARVDELAY as the criterion and again repeated with HNDDELAY as the criterion.

As the analyses were performed on the same sample, the alpha level was adjusted to control the Type I error rate, using the Bonferioni procedure (Dunn, 1961; Kirk, 1968; Miller, 1966). Following this adjustment, only results that were $\leq .014$ were considered significant.

\section{RESULTS}

\section{Air Traffic Safety (ATSAFE)}

The correlations between ATSAFE, TMC, and VIDEO are presented in Table 3. The correlation between ATSAFE and the predictor (VIDEO) was low but significant $(r=.12, N=404, p \leq .05)$. The correlation between ATSAFE and the cognitive aptitude measure (TMC) was significant $(r=.19, N=$ $404, p \leq .01$ ). Results from the regression analysis for ATSAFE are presented in Table 4. The performance variable (ATSAFE) was regressed on the Transmuted Composite score (TMC) and the predictor variable (VIDEO) using a forward hierarchical stepwise variable selection strategy. TMC was entered first into the regression $\left(R^{2}=.037, F=15.60, p \leq .001\right)$, and accounted for $4 \%$ of the variance in ATSAFE. Selfreported experience on various video games (VIDEO) accounted for an additional $1.3 \%$ of the variance in $\operatorname{ATSAFE}\left(\Delta R^{2}=.013, F=10.674, p \leq .001\right)$.

\section{Arrival Delay (ARVDELAY)}

The correlation between ARVDELAY and (VIDEO) was $r=.20,(N=404, p \leq .01)$. The correlation between ARVDELAY and TMC was lower ( $r=$ $.15, N=404, p \leq .01)$. Results from the regression analysis for ARVDELAY are presented in Table 5. The criterion (ARVDELAY) was regressed on the Transmuted Composite score (TMC) and the predictor variable VIDEO using a forward hierarchical stepwise variable selection strategy. TMC was entered first into the equation and accounted for $2 \%$ of the variance in $\operatorname{ARVDELAY}\left(R^{2}=.023, F=8.945, p \leq .05\right)$. Self-reported experience on various video games (VIDEO) accounted for an additional $3.6 \%$ of the variance in ARVDELAY $\left(\Delta R^{2}=.036, F=12.315, p \leq .001\right)$.

\section{Hand-off Delay (HNDDELAY)}

The correlation between HNDDELAY and the predictor (VIDEO) was $r=.30,(N=404, p \leq .01)$. The correlation between HNDDELAY and TMC was lower $(r=.16, N=404, p \leq .01)$. Results from the regression analysis for HNDDELAY are presented in Table 6. The criterion variable (HNDDELAY) was regressed on the Transmuted Composite score (TMC) and the predictor variable (VIDEO) using a forward hierarchical stepwise variable selection strategy. TMC was entered first into the equation and accounted for $3 \%$ of the variance in HNDDELAY $\left(R^{2}=.026\right.$, $F=10.733, p \leq .01)$. Self-reported experience on various video games (VIDEO) accounted for an additional $9 \%$ of the variance in HNDDELAY $\left(\Delta R^{2}=.087, F=25.488, p \leq .001\right)$. 
TABLE 3

Correlations between cognitive aptitude (TMC), predictor (VIDEO), and the performance criteria

\begin{tabular}{llllll}
\hline & TMC & VIDEO & ATSAFE & ARVDELAY & HNDDELAY \\
\hline TMC & & & & \\
VIDEO & .041 & & & \\
ATSAFE & $.193^{\star *}$ & $.123^{*}$ & & \\
ARVDELAY & $.148^{\star *}$ & $.196^{\star *}$ & .032 & \\
HNDDELAY & $.161^{\star *}$ & $.301^{* \star}$ & $.215^{* *}$ & $.295^{\star * *}$ \\
\hline
\end{tabular}

TABLE 4

Results of stepwise hierarchical regression analysis on ATSAFE variable

\begin{tabular}{lcccc}
\hline Model & $R^{2}$ & $\Delta R^{2}$ & $\Delta F$ & $F$ \\
\hline TMC & .037 & & & $15.60^{\star \star \star}$ \\
VIDEO & .050 & .013 & $5.57^{\star}$ & $10.67^{\star \star \star}$ \\
\hline
\end{tabular}

TABLE 5

Results of stepwise hierarchical regression analysis on ARVDELAY variable

\begin{tabular}{lcccc}
\hline Model & $R^{2}$ & $\Delta R^{2}$ & $\Delta F$ & $F$ \\
\hline TMC & .023 & & & $8.95^{\star \star}$ \\
VIDEO & .058 & .036 & $15.37^{\star \star \star}$ & $12.32^{\star \star \star}$ \\
\hline
\end{tabular}

TABLE 6

Results of stepwise hierarchical regression analysis on HNDDELAY variable

\begin{tabular}{|c|c|c|c|c|}
\hline Model & $R^{2}$ & $\Delta R^{2}$ & $\Delta \boldsymbol{F}$ & $F$ \\
\hline$\overline{\text { TMC }}$ & .026 & & & $10.73^{\star *}$ \\
\hline VIDEO & .113 & .087 & $39.22^{* * *}$ & $25.49^{\star \star * *}$ \\
\hline
\end{tabular}




\section{DISCUSSION}

Self-reported experience on video games was found to be significantly related to ARVDELAY and HNDDELAY at the adjusted significance level of $p \leq$ .014 . These results suggested that those persons with video game experience were more efficient in handling hand-offs and the routing of aircraft in such a way as to minimize arrival delays. In short, those with video game experience were faster.

At first glance, these results seem at odds with those reported in the initial ASI validation studies. However, the ASI findings related to the effects of computer and video game experience on composite scores in predicting screen success. The current study dealt with video game experience on ATST scores, specifically. Moreover, delay scores were not considered in the scoring equation at the time of the original validation studies. None the less, scores earned on the ATST were the most heavily weighted components of the PTS composite, and these results suggest that further research is needed to investigate any moderating effects these findings may have on composite scores. That research might include delay.

Additionally, it should be noted that the criterion measures were computed from data obtained on the last day of screening. A considerable amount of learning had taken place by this time. We suspect that a much larger effect size might have been noted during the early learning phases, but our concern here was with the effect upon composite scores. Future research could investigate the impact of prior video game experience on learning curves and strategies used in the work sample test.

\section{REFERENCES}

Aerospace Sciences, Inc. (1991). ATCS PTS Preliminary Validation: Final report. (Final report delivered under contract DTFA01-90-01034). Washington, DC: Federal Aviation Administration Office of the Deputy Administrator.

Bliss, J; Kennedy, R. S; Turnage, J; Dunlap, W. (1991). Communality of videogame performances with tracking tasks. Perceptual \& Motor Skills, 73(1), 22-30.
Booth-Kewley, S., Edwards, J. E., \& Rosenfeld, P. (1992). Impression management, social desirability, and computer administration of attitude questionnaires: Does the computer make a difference? Journal of Applied Psychology, Z7, 562-566.

Broach, D., \& Aul, J.C. (1993). Analysis of the air traffic control specialist (ATCS) occupation using the Position Analysis Questionnaire (PAQ). Unpublished manuscript.

Brokaw, L. D. (1984). Early research on controller selection. In S.B.Sells, J.T. Dailey, \& E.W. Pickrel (Eds.), Selection of air traffic controllers, pp. 39-78. (DOT/FAA/AM-84/2). Washington, DC: Federal Aviation Administration Office of Aviation Medicine. NTIS\#ADA147765.

Burke, M. J. (1992). Computerized psychological testing: Impacts on measuring predictor constructs and future job behavior. In N. Schmitt, W. C. Borman, \& Associates (Eds.), Personnel selection in organizations. San Francisco: Jossey-Bass.

Collins, W.E., Booone, J. O., \& VanDeventer, A. D. (1984). The selection of air traffic control specialist: Contributions by the Civil Aeromedical Institute. In S.B. Sells, J. T. Dailey, \& E. W. Pickrel (Eds.), Selection of air traffic controllers. pp. 79 112. (DOT/FAA/AM-84/2). Washington, DC: Federal Aviation Administration Office of Aviation Medicine. NTIS\#ADA1 47765.

Dorval, Michel, Pepin, Machel (1986). Effect of playing a video game on a measure of spatial visualization. Perceptual \& Motor Skills. 62(1), 159-162.

Dunn, O.J. (1961). Multiple comparisons among means. Journal of the American Statistical Association, 56, 52-64, (1961).

Finegan, J. E., \& Allen, N. J. (1994). Computerized and written questionnaires: Are they equivalent? $\mathrm{Com}$ puters in Human Behavior, 10, 483-496.

Human Technology, Inc. (1991). Cognitive task analysis of en route air traffic control: Model extension and validation. Volume I: Report. (Final report delivered under Office of Personnel Management contract OPM-87-9041). Washington, DC: Federal Aviation Administration Office of Training and Higher Education.

King, W. C., \& Miles, E. W. (In press). A quasiexperimental assessment of the effect of computerizing non cognitive pencil-and-paper measurements: A test of measurement equivalence. Journal of Applied Psychology. 
Kirk, R. E. (1968). Experimental design: Procedures for the behavioral sciences. Belmont, Calif: Brooks/Cole.

Koson, D., Kitchen, C., Kochen, M., \& Stodolosky, D. (1970). Psychological testing by computer: Effect of response bias. Educational and Psychological Measurement, 30, 803-10.

Lautenschlager, G. J., \& Flaherty, V.L. (1990). Computer administration of questions: More desirable or more social desirability? Journal of Applied Psychology, 75, 310-14.

Lee, Jo A., (1986). The effects of past computer experience on computerized aptitude test performance. Educational and Psychological Measurement. 뜨, 727-33.

Lee, J., Moreno, K. E., \& Sympson, J. B. (1986). The effects of mode of test administration on test performance. Educational and Psychological Measurement, $\underline{46}$, 467-74.

Lohman, D. F. (1979). Spatial ability: A review and re analysis of the correlational literature (Tech. Rep. No. 8). Stanford, CA: Stanford University, School of Education.

Lukin, M. E., Dowd, T., Plake, B. S., \& Kraft, R. G. (1985). Comparing the computerized MMPI. Journal of Personality Assessment, 13 , 407-12.

Lushene, R. E., O’Neil, H. F., \& Dunn, T. (1974). Equivalent validity of a completely computerized MMPI. Journal of Personality Assessment, 38, 353-61.

Manning, C. A. (1991). Procedures for selection of air traffic control specialists. In $\mathrm{H}$. Wing \& C. A. Manning (Eds.), Selection of air traffic controllers: Complexity, requirements, and public interest, $\mathrm{pp}$. 13-22. (DOT/FAA/AM-91/9). Washington, DC: Federal Aviation Administration Office of Aviation Medicine. NTIS \#AD A238267.

Martin, C. L., \& Nagao, D. H. (1989). Some effects of computerized interviewing on job applicant responses. Journal of Applied Psychology, Z4 , 72-80.

Mazzeo, J., \& Harvey, A. L. (1988). The equivalence of scores from automated and conventional educational and psychological tests: $A$ review of the literature. (College Board Report No.88-8/Educational Testing Service Research Report No. 88-21). New York: College Entrance Examination Board.
Mead, A. D., \& Drasgow, F. (1993). Equivalence of computerized and paper-and-pencil cognitive ability tests: A meta-analysis. Psychological Bulletin, 114, 449-59.

Miller, R. G., Jr. (1966). Simultaneous statistical inference. New York: McGraw-Hill, 1966.

Potosky, D. (1996). Beliefs about computers and their subsequent effects on response distortion. Unpublished doctoral dissertation, Rutgers, the State University of New Jersey.

Rabbitt, P.; Banerji, N.; Szymanski, A. (1989). Space Fortress as an IQ test? Predictions of learning and of practised performance in a complex interactive video-game. Special Issue: The Learning Strategies program: An examination of the strategies in skill acquisition. Acta Psychologica. Z1, 243-57.

Rock, D. B., Dailey, J. T., Ozur, H., Boone, J. O., \& Pickrel, E. W. (1984a). Validity and utility of the ATC experimental test battery. Study of Academy trainees, 1982. In S. B. Sells, J. T. Dailey, \& E. W. Pickrel (Eds.). Selection of air traffic controllers (pp. 459 - 502). (DOT/FAA/AM-84/2). Washington, DC: Federal Aviation Administration Office of Aviation Medicine. NTIS\#ADA147765.

Rosenfeld, P., Giacalone, R. A., Knouse, S. B., Doherty, L. M., Mitchell-Vicino, S., Kantor, J., \& Greaves, J. (1991). Impression management, candor, and microcomputer-based organizational surveys: An individual differences approach. Computers in Human Behavior, Z, 23-32.

Sells, S. B., Dailey, J. T., \& Pickrel, E. W. (Eds.) (1984). Selection of air traffic controllers. (DOT/FAA/AM84/2). Washington, DC: Federal Aviation Administration Office of Aviation Medicine. NTIS\#ADA147765.

Vansickle, T. R., Kimmel, C., \& Kapes, J. T. (1989). Test-retest equivalency of the computer-based and paper-and-pencil versions of the Strong-Campbell Interest Inventory. Measurement and Evaluation in Counseling and Development, 22, 88-93.

Wilson, F. R., Genco, K. T., \& Yager, G. G. (1985). Assessing the equivalence of paper-and-pencil vs. commputerized tests: Demonstration of a promising methodology. Computers in Human Behavior, $1,265-75$. 


\section{APPENDIX A \\ COMPUTER USAGE SURVEY}

The purpose of this survey is to assess your level of experience on computers and video games. Please read each question carefully and mark the response that best reflects your experience on the FAA General Answer Sheet. Your response to each question represents a critical aspect of this research.

For questions $1-8$, use the following scale to estimate how many times in the past year you have done the following:

$$
\begin{aligned}
& A=\text { Never } \\
& B=\text { Seldom } \\
& C=\text { Sometimes } \\
& D=\text { Frequently } \\
& E=\text { Often }
\end{aligned}
$$

1. Used a typewriter?

2. Used a computer?

3. Used a computer for writing or word processing?

4. Used a computer for developing budgets?

5. Used computer programming languages (e.g. BASIC, FORTRAN, or C-Language)?

6. Played home computer games (software games for a personal computer)?

7. Played home video games (hook up to a television set, such as Nintendo or Atari)?

8. Played video arcade games (stand-alone units that usually cost a quarter)?

For questions 9-17, indicate your answer using the following scale:

$$
\begin{aligned}
& A=\text { Yes } \\
& B=\text { No }
\end{aligned}
$$

9. Have you ever had a course in typing?

10. Have you ever had a course on the use of a computer?

11. Have you ever had a course in word processing on a computer?

12. Have you ever had a course on computer programming?

13. Have you ever had a course on computer repair?

14. Do you own a typewriter?

(continued on next page) 